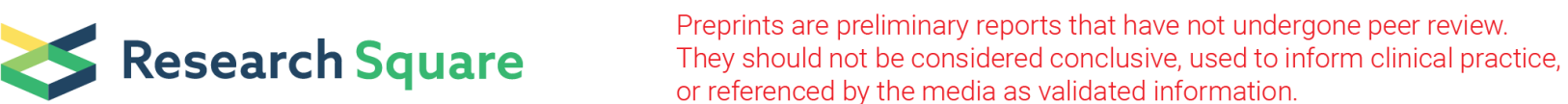

\section{Risk Areas and Spatial Variations in Temporal Trends of Pulmonary Tuberculosis and Their Determinants in a High Burden City From São Paulo State- Brazil.}

Thaís Zamboni Berra ( $\nabla$ thaiszamboni@live.com )

University of Sao Paulo: Universidade de Sao Paulo https://orcid.org/0000-0002-4163-8719

Antônio Carlos Vieira Ramos

University of Sao Paulo: Universidade de Sao Paulo

Luiz Henrique Arroyo

University of Sao Paulo: Universidade de Sao Paulo

Juliane de Almeida Crispim

University of Sao Paulo: Universidade de Sao Paulo

Yan Mathias Alves

University of Sao Paulo: Universidade de Sao Paulo

Felipe Lima dos Santos

University of Sao Paulo: Universidade de Sao Paulo

Fernanda Bruzadelli Paulino da Costa

University of Sao Paulo: Universidade de Sao Paulo

Márcio Souza dos Santos

University of Sao Paulo: Universidade de Sao Paulo

Luana Seles Alves

University of Sao Paulo: Universidade de Sao Paulo

Regina Célia Fiorati

University of Sao Paulo: Universidade de Sao Paulo

Aline Aparecida Monroe

University of Sao Paulo: Universidade de Sao Paulo

Dulce Gomes

Universidade de Évora: Universidade de Evora

Ricardo Alexandre Arcêncio

University of Sao Paulo: Universidade de Sao Paulo

Research

Keywords: tuberculosis, spatial analysis, temporal trend

Posted Date: November 12th, 2020

DOl: https://doi.org/10.21203/rs.3.rs-104389/v1 
License: (우 (i) This work is licensed under a Creative Commons Attribution 4.0 International License. Read Full License 


\section{Abstract}

\section{BACKGROUND}

Tuberculosis is the leading cause of global deaths from a single infectious agent. This study aimed to identify areas of spatial and space-time risk for pulmonary tuberculosis, to identify areas with variation in the temporal tendency for this event, and to identify factors associated with the epidemiological situation in one municipality.

\section{METHODS}

An ecological study carried out in Ribeirão Preto, São Paulo, Brazil. The population consisted of pulmonary tuberculosis cases reported in the Tuberculosis Patient Control System between 2006 to 2017. To check the behavior of tuberculosis over the period, the Seasonal Trend Decomposition using Loess decomposition method was used. Spatial and spatiotemporal scanning statistics were used to identify risk areas, and Spatial Variation in Temporal Trends (SVTT) was used to detect clusters with changes in the temporal trend. Finally, Pearson's chisquare test was performed to identify factors associated with the epidemiological situation in the municipality.

\section{RESULTS}

Between 2006 and 2017, 1760 cases of pulmonary tuberculosis were reported in the municipality. With spatial scanning, four groups of clusters were identified with relative risks (RR) from 0.19 to 0.52 (95\%Cl:0.09-0.69); 1.73 (95\%Cl:1.49-1.99); 2.07 (95\% Cl:1.70-2.32) and from 2.68 to 2.72 (95\% Cl:2.00-3.77). With the space-time scan, four clusters were also identified with RR of 0.13 [2008-2013] (95\%Cl:0.03-0.26); 1.94 [2010-2015] (95\%Cl:1.77$2.11) ; 2.34$ [2006 to 2011] (95\%Cl:1.67-2.94) and 2.84 [2014-2017] (95\%Cl:2.50-3.90). With the SVTT, a cluster was identified with RR 0.11 , an internal time trend of growth (+0.09\%/year) and an external one of decrease $(-0.06 \% / y e a r)$. Finally, three risk factors and three protective factors associated with the epidemiological situation in the municipality were identified, being: race/brown color (OR: 1.26), without education (OR: 1.71), retired (OR: 1.35), 15 years old or more of study (OR: 0.73), not having HIV (OR: 0.55) and not having diabetes (OR: 0.35).

\section{CONCLUSION}

The importance of using spatial analysis tools in the identification of areas that should be prioritized is highlighted, and greater attention is needed to individuals who fit the profile indicated as risk for the disease, in order to undertake social and health actions in an attempt decrease the mortality of the disease.

\section{Background}

Tuberculosis is one of the oldest diseases in the world and is still the cause of illness for millions of people each year. According to the World Health Organization (WHO), tuberculosis is the leading cause of death from a single infectious agent in the world and is also the leading cause of death among people living with the human immunodeficiency virus (PLHIV)[1].

It is estimated that in 2018 there were approximately seven million cases of tuberculosis in the world, with $57 \%$ of these cases affecting males, $32 \%$ females and $11 \%$ children under 15 years of age. In addition to these alarming statistics, the WHO still estimates that there were 1.2 million deaths from tuberculosis and more than 250,000 deaths caused by co-infection with tuberculosis and human immunodeficiency virus (TB-HIV)[1]. 
Brazil occupies the $20^{\text {th }}$ position among the 30 countries that concentrate $90 \%$ of the global burden of tuberculosis, and in 2018, more than 73,000 new cases of tuberculosis were registered in the country, indicating a detection coefficient of 35.0 cases/100,000 inhabitants, 13,610 cases of retreatment and approximately 500 new cases of drug resistance[2].

Tuberculosis can present in two forms, pulmonary and extrapulmonary. Pulmonary tuberculosis, in addition to being the most frequent form, is the most important in terms of public health since it is responsible for the chain of transmission of the disease. The main symptoms include fever, night sweats, fatigue, productive cough for more than 3 weeks, and, in more advanced cases, hemoptysis[2].

The active search for respiratory symptoms and the rapid start of treatment are central elements for the control of the disease, which allows for the early detection of pulmonary forms, but for extrapulmonary forms, their signs and symptoms may vary according to the affected organs[3]. The exposure highlights the importance of identifying areas of risk of tuberculosis occurrence in order to assist managers in making decisions for the confrontation of the disease, especially in priority áreas.

It is known that the incidence of any disease changes over time and that the time trend also varies according to the geographic region. Thus, the importance of monitoring the emerging spatial patterns and temporal risk trends for tuberculosis is emphasized in order to provide additional information to help prevent, implement control measures and address new health risks[4].

Therefore, this study aimed to identify areas of spatial and space-time risk for pulmonary tuberculosis, to identify areas with spatial variation in temporal trends for this event and to identify factors associated with the epidemiological situation of the municipality.

\section{Methods}

\section{Research design and scenario}

An ecological study[7] was carried out in Ribeirão Preto, a city in the interior of the state of São Paulo (SP). Located 314 kilometers $(\mathrm{km})$ from the capital, Ribeirão Preto has an area of approximately 650 square kilometers $\left(\mathrm{km}^{2}\right)$ and a high population density of 995.3 inhabitants $/ \mathrm{km}^{2}$. It also had an estimated population of 711,825 inhabitants in 2020, of which $99.7 \%$ live in urban áreas[8].

The ecological analysis units of the study are the census sectors in the municipality. The census sector is the smallest territorial unit formed by a continuous area, located in an urban or rural area, with a defined size, number of households and number of residents, and is used for the main Brazilian statistical surveys[9].

Figure 1 shows the geographical location of the municipality of Ribeirão Preto, which is divided into 972 census sectors, however, for this study it was decided to use only the urban census sectors in the municipality, corresponding to 956 units of analysis. The cartographic base of the census sectors in Ribeirão Preto was obtained from the website of the Brazilian Institute of Geography and Statistics (IBGE)[9] free of charge.

Regarding tuberculosis, the city is considered one of the 22 priority municipalities in the state of São Paulo due to the high number of cases; in the last nine years, there was an average of 196 cases/year, with an incidence rate of around 35/100,000 inhabitants[10]. 
The active search for respiratory symptoms with sputum smear collection and X-ray order is performed by all basic health units (Ribeirão Preto has 44 health units in Primary Care), however, the treatment and monitoring of the disease is carried out in the five specialized district infectology clinics. In addition, the directly observed treatment is offered to all patients diagnosed with tuberculosis and is carried out by the outpatient teams[10].

\section{Population}

The study population consisted of all confirmed cases of pulmonary tuberculosis reported in the Tuberculosis Control System (TBWeb) from 2006 to 2017, made available by the Municipal Tuberculosis Control Program of the Ribeirão Preto Municipal Secretariat.

It is worth mentioning that in Brazil, the notification of tuberculosis is carried out through the Information System for Notifiable Diseases (SINAN), however the state of São Paulo uses its own unique system for notification and monitoring of people with tuberculosis, but which also interfaces with SINAN. The system, called TBWeb, started to be used effectively from the year 2006 and the notifications are made online, the main advantage being the exclusivity of the medical record of each person notified with tuberculosis and automatic communication in cases of transfer and hospitalization[11].

It was adopted as a selection criterion that the notification was carried out between 2006 and 2017, with only one registration per person, the most current registration being selected if there was more than one entry in the system and residents in an urban area of the city of Ribeirão Preto. It is noteworthy that only pulmonary tuberculosis records were considered, so that extrapulmonary or concomitant forms (pulmonary and extrapulmonary forms together) were excluded.

\section{Analysis plan}

\section{Time series analysis}

Initially, monthly time series of tuberculosis cases were constructed, referring to the period from January 2006 to December 2017. To verify the behavior of the time series over the study period and also its trend, the decomposition method called Seasonal Trend Decomposition using Loess (STL) was used, which is based on a locally weighted regression[12]. This analysis was performed using RStudio software through the forecast package[13].

\section{Identification of clusters}

The georeferencing of pulmonary tuberculosis cases was performed using the Google Earth Pro ${ }^{\circledR}$ software in order to obtain the geographical coordinates (latitude and longitude) of the residential addresses of the notified cases.

In order to identify areas at higher risk for pulmonary tuberculosis, the spatial analysis technique called scanning statistics, developed by Kulldorff and Nagarwalla[14], was used.

The identification of clusters was carried out by placing a circle of variable radius around the centroid of each unit of analysis (census sector) and the number of observed and expected cases is calculated. This procedure is performed until all centroids are tested and, when the value observed in the area enclosed by the circle is greater or less than expected, it is called a cluster[15]. 
It is considered as a null hypothesis that there is no high or low risk cluster, that is, the entire population has the same probability of contracting pulmonary tuberculosis, regardless of its location; while the alternative hypothesis assumes the existence of clusters that are areas in which the population would be more or less likely to contract the disease[14].

Unlike the purely spatial scan that is based on circles, in the space-time scan, cylinders are created around each centroid, in which the base of the circle remains the same, and additionally, the height of that cylinder reflects the period of time considered in the cluster, so as to move through time and space simultaneously[15]. Thus, incorporating time as a variable of interest, it is possible to verify the existence of clusters in a given area, and that in a specific period of time, there was a greater or lesser proportion of cases when compared to the other areas analyzed[15].

Still referring to the analysis of cluster detection, the SVTT technique was also performed, which differs from the other analyses presented by calculating the temporal trend of the clusters[4].

This analysis uses the same circles as the purely spatial scan, however, the SVTT does not seek to identify clusters with a high or low number of occurrences of the event, but verifies whether the time trend of the cases is increasing or decreasing over time[15].

The time trend is calculated inside and outside the scan circle, in which we call the internal temporal trend (ITT) the change in the time trend of the event within a cluster, and the external temporal trend (ETT) as the trend of all

other areas that do not belong to the cluster in question. Therefore, what is statistically significant in this analysis are the temporal trends and not the formation of a cluster as in spatial and space-time scanning $[4,16]$.

In SVTT, it is considered as a null hypothesis when there is no difference in the temporal trends in the analyzed areas and we have as an alternative hypothesis that the temporal trends are different.

The parameters used in the analysis of purely spatial scanning, space-time scanning, and SVTT were: discrete Poisson model, no geographic overlap of clusters, circular-shaped clusters, 999 replications in the Monte Carlo simulation, and the size of the exposed population was $8 \%$, value stipulated by the Gini coefficient in which the number of cases is compared to the data of the base population and the expected number of cases in each census sector is proportional to the size of the population at risk[15,17].

In addition, the relative risk (RR) and 95\% confidence interval $(95 \% \mathrm{Cl})$ of each cluster was calculated, allowing the comparison of information in different areas, with the exception of SVTT because, as explained above, it is emphasized that what is significant in this analysis are ITT and ETT, so that the RR of the identified cluster may not be within the $\mathrm{Cl}$. Clusters with $\mathrm{p}<0.05$ were considered statistically significant.

The analyses were performed using SaTScan software version 9.3, and thematic maps were created using ArcGis software version 10.5 .

\section{Descriptive and association analysis}

In order to identify factors associated with the epidemiological situation that occurred in the municipality, exploratory analyses (absolute and relative frequencies) were carried out, and then, the association of these variables with the fact of living in a risk area identified through the Pearson's chi-square analysis $\left(X^{2}\right)$ and for the 
variables that were statistically significant $(\mathrm{p}<0.05)$, Odds Ratio $(\mathrm{OR})$ and $95 \% \mathrm{CI}$ were calculated using the IBM SPSS version 25 software.

\section{Results}

Between 2006 and 2017, 2259 tuberculosis cases were reported in Ribeirão Preto, of which 1760 (77.9\%) were pulmonary tuberculosis. The minimum age of the cases was 2 months and the maximum was 102 years old, with an average of 42 years old and a median of 41 years old.

Figure 2 shows the behavior of the pulmonary tuberculosis time series and its time trend over the study period, in which it is possible to observe the presence of peaks and falls in certain periods of the years.

Then, in the stage of spatial analysis, of the 1760 cases of pulmonary tuberculosis reported in the period, 112 cases were excluded because they were residents of a rural area of the municipality, the address field on the notification form was blank, incomplete, or contained the address of units health and/or being a population deprived of liberty, so that it was not possible to perform georeferencing. Therefore, of the 1760 cases of pulmonary tuberculosis, 1648 cases (93.6\%) were georeferenced and integrated in the following analyses.

With the application of the purely spatial scanning technique, it was possible to identify four groups of statistically significant clusters $(p<0.01$ ) (Figure 3 ), corroborating the alternative hypothesis that there are areas in the municipality with a greater or lesser risk for illness from pulmonary tuberculosis.

Spatial cluster 1 (SC1), considered as protection for the event, presented RR: 0.19 to 0.52 (95\% Cl: 0.09-0.69), composed of 238 census sectors in the eastern, western and central districts of the municipality, with a population of 129,233 inhabitants, 131 expected cases and 215 cases of pulmonary tuberculosis, with an average annual rate of 7.8 cases/100,000 inhabitants.

Spatial cluster 2 (SC2) with RR: 1.73 (95\% Cl: 1.49-1.99), was composed of 60 census sectors in the west district, two census sectors in the central district, and two census sectors in the north district, with a population of 48,190 inhabitants, 131 expected cases and 215 cases of pulmonary tuberculosis observed, with an average annual rate of 37.2 cases $/ 100,000$ inhabitants.

Spatial cluster 3 (SC3), presented RR: 2.07 (95\% Cl:1.70-2.32), was composed of 52 census sectors in the north district and two census sectors in the central district, with a population of 34,919 inhabitants, 92 expected cases and 180 observed cases of pulmonary tuberculosis, with an average annual rate of 44.6 cases/100,000 inhabitants.

Finally, spatial cluster 4 (SC4) with RR: 2.68 to 2.72 (95\% Cl:2.00-3.77), was composed of 24 census sectors in the southern district, with a population of 20,243 inhabitants, 52 expected cases and 138 observed cases of tuberculosis pulmonary disease, with an average annual rate of 59.9 cases/100,000 inhabitants.

With the space-time scan, it was possible to identify four statistically significant clusters $(p<0.01)$, one being protective and three at risk for pulmonary tuberculosis (Figure 4). The space-time cluster 1 (STC1), considered as protection for the event, presented RR: 0.13 (95\% Cl:0.03-0.26) between the years 2008 and 2013, was composed of 87 census sectors in the eastern district, with a population of 46,781 inhabitants, 66 expected cases and 9 observed cases of pulmonary tuberculosis, with an average annual rate of 3.1 cases/100,000 inhabitants.

Page $7 / 22$ 
The space-time cluster 2 (STC2) presented RR: 1.94 (95\% Cl:1.77-2.11) between the years 2010 and 2015, it was composed of 58 census sectors in the west district, 4 in the north district, and two census sectors in the central district, with a population of 48,190 inhabitants, 66 expected cases and 123 observed cases of pulmonary tuberculosis, with an average annual rate of 42.6 cases $/ 100,000$ inhabitants.

The space-time cluster 3 (STC3), with RR: 2.34 (95\% Cl:1.67-2.94) and the period from 2006 to 2011, was composed of 44 census sectors in the northern district, with a population of 27,700 inhabitants, 36 expected cases and 82 cases of pulmonary tuberculosis observed, with an average annual rate of 51.8 cases/100,000 inhabitants.

Finally, space-time cluster 4 (STC4) ( $<$ <.01) presented RR: 2.84 (95\% Cl:2.50-3.90) between the years 2014 and 2017, it was composed of 20 census sectors in the southern district, with a population of 19,386 inhabitants, 16 expected cases and 46 observed cases of pulmonary tuberculosis, with an average annual rate of 63.5 cases/100,000 inhabitants.

With the application of SVTT, it was found that the cases of pulmonary tuberculosis in Ribeirão Preto showed an average decrease of $0.12 \%$ per year, making the findings presented in Figure 2 in which periods of peaks and falls were clearer. Still, with this analysis, it was possible to identify a cluster with a statistically significant variation in the temporal trend $(p<0.01)$ (Figure 5).

The cluster with spatial variation in temporal trends 1 (SVTT1) has RR: 0.11 and was composed of 13 census sectors in the eastern district of the municipality, with a population of 6,223 inhabitants, 17 expected cases and 2 observed cases of pulmonary tuberculosis, with an average annual rate 2.6 cases $/ 100,000$ inhabitants. The cluster, classified as protection for the event, presented an ITT of growth $(+0.09 \%$ per year), while the ETT indicated a decrease ( $-0.06 \%$ per year).

Finally, Table 1 shows the clinical-epidemiological profile of all pulmonary tuberculosis cases reported in Ribeirão Preto from 2006 to 2017 and the clinical-epidemiological profile of cases of pulmonary tuberculosis resident in the clusters identified with the techniques of the scan applied.

From the analysis of $\mathrm{X}^{2}$ and $\mathrm{OR}$ it was possible to identify three risk factors and three protective factors associated with the epidemiological situation in the municipality. In the identified areas, people of race/color brown are 1.26 times more likely to fall ill with pulmonary tuberculosis, as well as people without any study (OR: 1.71) and retirees (OR: 1.35).

Higher education (15 years or more of study) was identified as a protective factor against tuberculosis in the identified areas (OR: 0.73). Also classified as protection for the event are human immunodeficiency virus (HIV) negative people who do not have diabetes (OR: 0.55 and 0.35 , respectively).

Table 1. Clinical and epidemiological profile of pulmonary tuberculosis cases and factors related to living in a risk area, Ribeirão Preto, SP, Brazil (2006-2017)

\section{Discussion}

When analyzing the time series of pulmonary tuberculosis cases between 2006 and 2017, it was possible to observe a series of undulations in its temporal trend, which was later classified through the SVTT, which indicated 
an average decrease of $0.12 \%$ per year of pulmonary tuberculosis in Ribeirão Preto.

In Brazil, in general, between 2009 and 2018 there was an average annual drop of about 1\% in the incidence rate of tuberculosis in the country[18], therefore, this drop in pulmonary tuberculosis cases in Ribeirão Preto may be a reflection of actions and policies to combat tuberculosis that may be successful. However, it is worth highlighting the possibility that new cases may not be being diagnosed and/or reported and that this time trend is considered to be decreasing as an alert so that municipal managers can identify situations in which the reported data differ from the real behavior of the disease in the municipality[19].

With the analysis of purely spatial scanning, it was possible to verify the formation of clusters in areas that can be considered at risk for the occurrence and transmissibility of pulmonary tuberculosis.

SC4, classified with the highest RR (RR: 2.68 to 2.72), was located in the southern district where the largest subnormal agglomerate in the number of residents is found in the municipality, and it is noteworthy that Family Health Units have not yet been implemented in this área[20-21]. SC3 (RR: 2.07), located mostly in the northern district, is the region with the highest population density in the municipality and also concentrates the largest number of residents per residence. It is noteworthy that in this district, there is a settlement of rural workers and this region also concentrates the largest number of subnormal agglomerates (slums) in the city[21].

The SC2 (RR: 1.73) identified in the western district of the municipality, which also had an area classified as protection against pulmonary tuberculosis, has one of the lowest municipal human development rates in the city, with the population receiving mostly two minimum wages. It is the region with the largest number of health units and has the highest percentage of exclusive users of the Unified Health System (SUS) in the city[21].

Finally, SC1 was classified as protection for the event (RR: 0.19 to 0.52 ) and located in the eastern, western, and central districts. It is noteworthy that the center of Ribeirão Preto had the lowest density of inhabitants per residence and presents mainly commercial properties. In the eastern district, the population has the highest municipal income and also the highest level of education. It is noteworthy that this region has areas of expansion of high standard condominiums, however, there are also population clusters with lower socioeconomic resources that deserve attention[20-21].

As already explored by other studies[22-25], the close relationship between tuberculosis and social vulnerability is emphasized and, in this way, it is understood that the understanding of tuberculosis as a disease related to the social determinants of health can help to expand strategies for coping with it.

With the use of the space-time scanning statistics, four statistically significant clusters were identified; one for protection (STC1; RR: 0.13) between the years 2008 and 2013 in the eastern district, which may indicate that during this period there were improvements in surveillance services in health, such as awareness campaigns and active search for respiratory symptoms or even if there were fewer diagnoses of the disease in this period or no notification of new cases.

With the association analysis, it was identified that, in the risk areas classified in the municipality, people of brown race/color were 1.26 times more likely to get sick with pulmonary tuberculosis. Other studies have shown that people of mixed race/color are less likely to be cured[31] and that the mortality rate from tuberculosis is growing in this population[32]. 
No plausible biological justification or relationship was found in the literature to justify this difference between brown race/color and other classifications, but the construction of Brazilian Society[33] and the social determinants of health[34] must be taken into account.

It is worth mentioning that in Brazil, the data on racial characteristics are obtained through self-declaration, so that it is the population itself that attributes the racial identity according to the IBGE classification, and it is also highlighted that it is expected that the number of self-declared blacks is less than browns due to miscegenation, characteristic of the Brazilian people.

Thus, a study identified that, in general, the living conditions of black and brown people in Brazil were always worse than those of the white population[35-36], so that, since the period of slavery, this population has been subjected to a greater burden of tropical diseases and illnesses and that this racial history of socioeconomic exclusion and precariousness in health reflects a set of disadvantages that, even today, can be observed in terms of social and health indicators[36-37].

The WHO highlights that this construction of racial differences is the basis for social and discriminatory divisions in various territories and contexts, and emphasizes that this racial division used is a social and not a biological category. In societies that have this marked characteristic of racial decriminalization, generally that group belonging to a certain category tends to be marginalized, so that this conformation affects all aspects of the individual's life, resulting in significantly worse health status than those belonging to other racial groups[34].

In addition, as a risk factor, it was identified that retirees living in classified areas were 1.35 times more likely to become ill from pulmonary tuberculosis. This increased risk can be justified by the fact that the majority of retirees are elderly people, and aging is associated with a series of changes in the body and organism, in addition to the greater risk for diseases associated with age such as cancer, heart disease and from infectious diseases, since there is a lower immune system with age[38-39].

It was also identified that people without any education had 1.71 times more chance, and people with high schooling (15 years or more of study) have less chance (OR: 0.73 ) of falling ill with pulmonary tuberculosis in high-risk areas in the municipality. In a literature review[40] conducted with the aim of relating the level of education to infection with Mycobacterium tuberculosis, it was identified that the educational level of people with tuberculosis is directly related to income, highlighting the relationship between tuberculosis and social conditions of life.

With low education, the majority of people affected by tuberculosis have professional activities consistent with the level of education they have as domestic employees, drivers, and construction workers. In addition, a review study[40] added that, generally, these people live in risky places, have inadequate food, and suffer deprivation of access to basic services (piped water, sewage network), which can negatively influence the immune system of individuals who live in such contexts.

Finally, it was also classified as protection for the event to be HIV negative and not to have diabetes (OR: 0.55 and 0.35 , respectively). It is known that HIV is an aggressive virus that attacks the immune system and, thus, the chances of contracting opportunistic infections such as tuberculosis are significantly increased. The impact of TB-HIV co-infection on the body is bidirectional as HIV increases the risk of infection and progression of 
tuberculosis, and tuberculosis slows the recovery of TCD4 cells destroyed by HIV, which increases the progression of the disease to AIDS and, consequently, deaths from tuberculosis in PLHIV[41-43].

The same happens in the case of people with tuberculosis and diabetes because tuberculosis makes glycemic control difficult and, in turn, high blood glucose aggravates tuberculosis[44-45]. It has been identified in studies[44-45] that people with diabetes have a 2.44 to 8.33 times greater chance of developing tuberculosis than those without the disease. This occurs because people with diabetes have decreased cellular and humoral immunity, in addition to hyperglycemia and cellular insulinopenia that have effects on the function of macrophages and lymphocytes, thus increasing the chance of infections[46-48].

With regard to limitations of this study, it was an ecological study; the so-called ecological fallacy stands out in that, because variables are used at the aggregate level, the results may not represent associations at the individual level[49]. It is also worth mentioning the use of secondary data sources, which may include incomplete data or typos.

In view of the above, using statistical techniques and spatial analysis to understand the behavior of the disease over time and the location of areas in the municipality in which tuberculosis is a problem, the characteristics of its surroundings, and to estimate the population at risk can assist managers in making assertive decisions, so that it becomes easier to understand the process about the chain of transmission of the disease and the entire context in which that population is inserted.

\section{Conclusions}

With the present study, it was possible to trace the behavior of tuberculosis over time in Ribeirão Preto, an endemic municipality and considered a priority for tuberculosis control and from the use of spatial analysis tools, areas were identified in which new efforts and measures should be prioritized, highlighting the active search for respiratory symptoms and their communicants, in addition to public awareness campaigns and education on the subject.

It is also necessary to pay more attention to individuals who fit the profile with characteristics indicated as risk for the disease, with emphasis on people of race / brown color, with low education, the elderly, PLHIV and diabetes, in order to undertake social and health actions. in an attempt to decrease the mortality of the disease, which mainly affects these most vulnerable populations.

\section{Abbreviations}

95\%Cl: 95\% confidence interval

ETT: external temporal trend

HIV: Human immunodeficiency virus

IBGE: Institute of Geography and Statistics

ITT: internal temporal trend

Km: kilometers

Page $11 / 22$ 
$\mathrm{Km}^{2}$ : square kilometers

OR: odds ratio

PLHIV: people living with the human immunodeficiency virus

RMT-TB: rapid molecular test for tuberculosis

RR: relative risk

SC1: spatial cluster 1

SC2: spatial cluster 2

SC3: spatial cluster 3

SC4: spatial cluster 4

SINAN: Information system for notifiable diseases

SP: São Paulo

STC1: space-time cluster 1

STC2: space-time cluster 2

STC3: space-time cluster 3

STC4: space-time cluster 4

STL: seasonal trend decomposition using Loess

SUS: unified health system

SVTT: spatial variation in temporal trends

SVTT1: cluster with spatial variation in temporal trends 1

TB-HIV: co-infection with tuberculosis and human immunodeficiency virus

TBWeb: Tuberculosis control system

WHO: World Health Organization

$\mathbf{X}^{2}$ : Pearson's chi-square analysis

\section{Declarations}

\section{Ethics approval and consent to participate}


In compliance with Resolution 499/2012 of the National Health Council, the study was approved by the Research Ethics Committee of Nursing College of Ribeirão Preto, University of São Paulo under the Certificate of Ethical Appraisal number 87696318.3.0000.5393 issued on April 30, 2019. Consent to participate was not applicable, because we worked with secondary data of cases diagnosed with tuberculosis and reported on TBWeb (tuberculosis case notification system used in the state of São Paulo).

\section{Consent for publication}

Not applicable

\section{Availability of data and materials}

The data that support the findings of this study are available from the Municipal Health Secretariat of Ribeirão Preto, but restrictions applied to the availability of these data, which were used under license for the current study, and so are not publicly available. Data are, however, available from the authors upon reasonable request and with permission of the Municipal Health Secretariat of Ribeirão Preto.

\section{Competing interests}

The authors declare that they have no competing interests.

\section{Funding}

This work was supported by the São Paulo State Research Support Foundation (FAPESP) (FAPESP Process $\mathrm{n}^{\circ}$ 2018/03700-7)

\section{Authors' contributions}

TZB, ACVR and RAA participated in the conception, planning, analysis, interpretation, and writing of the work; LHA, JAC, YMA, FBPC, MSS and LSA participated in the writing of the work; Author RCF, AAM and DG participated on interpretation and writing of the work. All authors have read and approved the final manuscript.

\section{Acknowledgements}

Municipal Health Secretariat of Ribeirão Preto

Municipal Tuberculosis Control Program of Ribeirão Preto

\section{References}

1. World Health Organization (WHO). Global Tuberculosis Report 2019. Geneva: World Health Organization; 2019. https://apps.who.int/iris/bitstream/handle/10665/329368/9789241565714-eng.pdf?ua=1. Accessed 26 Oct 2020.

2. Ministério da Saúde. Secretaria de Vigilância em Saúde. Boletim Epidemiológico - Tuberculose 2020, 40p. https://www.saude.gov.br/images/pdf/2020/marco/24/Boletim-tuberculose-2020-marcas--1-.pdf. Accessed 26 Oct 2020. 
3. Suárez I, Fünger SM, Kröger S, Rademacher J, Fätkenheuer G, Rybniker J. The Diagnosis and Treatment of Tuberculosis. Dtsch Arztebl Int. 2019;116:729-35.

4. Moraga P, Kulldorff M. Detection of spatial variations in temporal trends with a quadratic function. Stat Methods Med Res. 2016;25(4):1422-37.

5. Areias C, Briz T, Nunes C. Pulmonary tuberculosis space-time clustering and spatial variation in temporal trends in Portugal, 2000-2010: an updated analysis. Epidemiol Infect. 2015;143(15):3211-9.

6. Bruce ATI, Berra TZ, Santos FL, Alves YM, Souza LLL, Ramos ACV et al. Temporal trends in areas at risk for concomitant tuberculosis in a hyperendemic municipality in the Amazon region of Brazil. Infect Dis Poverty. 2020;109(1):111.

7. Kleinbaum DG, Kupper LL, Morgenstern H. Epidemiologic Research: Principles and Quantitative Methods. 1st ed. John Wiley \& Sons; 1982.

8. Instituto Brasileiro de Geografia e Estatística. Mapas: bases e referenciais. Rio de Janeiro: IBGE; 2010. http://mapas.ibge.gov.br/bases-ereferenciais/bases-cartograficas/cartas. Accessed 27 Oct 2020.

9. Instituto Brasileiro de Geografia e Estatística (IBGE). Malha de Setores Censitários. Rio de Janeiro: IBGE 2010.https://downloads.ibge.gov.br/downloads_geociencias.htm. Accessed 27 Oct 2020.

10. Ribeirão Preto. Prefeitura Municipal. Secretaria Municipal de Saúde. https://www.ribeiraopreto.sp.gov.br/ssaude/pdf/programas124.pdf. Accessed 27 Oct 2020.

11. Galesi VMN. Data on tuberculosis in the state of São Paulo, Brazil. Rev Saúde Pública. 2007;41(1):121.

12. Cleveland R, Cleveland W, McRee JE. Seasonal-trend decomposition procedure based on LOESS. J Offic Stat. 1990;6:3-73.

13. Hyndman R, Athanasopoulos G, Bergmeir C, Caceres G, Chhay L, O'Hara-Wild M et. al. Package 'forecast': Forecasting functions for time series and linear models. https://cran.r-

project.org/web/packages/forecast/forecast.pdf. Accessed 27 Oct 2020.

14. Kulldorff M, Nagarwalla N. Spatial disease clusters: Detection and inference. Statistics in Medicine. 1995;14(8)8:799-810.

15. Kulldorff M. SaTScan User Guide, 2018. https://www.satscan.org/cgibin/satscan/register.pl/SaTScan_Users_Guide.pdf?todo=process_userguide_download. Accessed 27 Oct 2020.

16. Jaisankar R, Kesavan J. A Study On Spatial Variations In Temporal Trends Of Dengue Incidences In Tamil Nadu, India. International Journal Of Scientific \& Technology Research. 2019;8(09).

17. Han J, Shu L, Kulldorff M, Hostovich S, Stinchcomb DG, Tatalovich Z et al. Using Gini coefficient to determining optimal cluster reporting sizes for spatial scan statistics. International Journal of Health Geographics. 2016;15:27.

18. Ministério da Saúde. Secretaria de Vigilância em Saúde. Boletim epidemiológico - Brasil livre da tuberculose: evolução dos cenários epidemiológicos e operacionais da doença. 2019: 50(9):18., 2019. https://portalarquivos2.saude.gov.br/images/pdf/2019/marco/22/2019-009.pdf. Accessed 27 Oct 2020.

19. Rodrigues MAF, Mota ELA. Subnotificação da Tuberculose: aplicação da metodologia captura-recaptura. Revista Baiana de Saúde Pública. 2016;40(2):70-90.

20. Berra TZ, Bruce ATI, Alves YM, Campoy LT, Arroyo LH, Crispim JA et al. Related factors, time trend and spatial association of abandonment of treatment for tuberculosis in Ribeirão Preto-SP. Eletr. Enferm. 2020; 22:1-10. 
21. Ribeirão Preto. Secretaria Municipal de Saúde, Departamento de Vigilância em Saúde e Planejamento. Fatores de risco relacionados à saúde da população residente na zona urbana de Ribeirão Preto (SP) 20082011. Ribeirão Preto (SP). http://www.ribeiraopreto.sp.gov.br/ssaude/vigilancia/vigep/fatores-risco.pdf. Accessed 27 Oct 2020.

22. Castro DB, Maciel EMGS, Sadahiro M, Pinto RC, Albuquerque BC, Braga JU. Tuberculosis incidence inequalities and its social determinants in Manaus from 2007 to 2016. Int J Equity Health. 2018;17(1):187

23. Santos DT, Alves LS, Arcoverde MAM, Arroyo LH, Berra TZ, Ramos ACV et al. Social risk and its association with tuberculosis mortality in a context of high inequality in South Brazil: A geo-epidemiology analysis. $\mathbf{J}$ Infect Public Health. 2020;13(8):1148-1155.

24. Berra TZ, Queiroz AAR, Yamamura M, Arroyo LH, Garcia MCC, Popolin MP et al. Spatial risk of tuberculosis mortality and social vulnerability in Northeast Brazil. Rev Soc Bras Med Trop. 2017;50(5):693-697.

25. Bertolozzi MR, Takahashi RF, França FOS, Hino P. A ocorrência da tuberculose e sua relação com as desigualdades sociais: Estudo de revisão Integrativa na Base PubMed. Anna Nery. 2019:24(1).

26. Ministério da Saúde. Secretaria de Vigilância em Saúde. Departamento de Vigilância das Doenças Transmissíveis. Rede de Teste Rápido para Tuberculose no Brasil: primeiro ano da implantação. Brasília: Ministério da Saúde, 2015. https://portalarquivos.saude.gov.br/images/pdf/2016/janeiro/19/rtr-tb-15jan16isbn-web.pdf. Accessed 27 Oct 2020.

27. Lima TM, Belotti NCU, Nardi SMT, Pedro HSP. GeneXpert MTB/RIF assay for diagnosis of tuberculosis. Rev Pan-Amaz Saude. 2017;8(2):67-78.

28. Shah W. To determine diagnostic accuracy of gene xpert and sputum Ziehl-Neelsen staining taking sputum culture as gold standard. European Respiratory Journal. 2016;48:PA2779.

29. Pandey P, Pant ND, Rijal KR, Shrestha B, Kattel S, Banjara MR et al. Diagnostic Accuracy of GeneXpert MTB/RIF Assay in Comparison to Conventional Drug Susceptibility Testing Method for the Diagnosis of Multidrug-Resistant Tuberculosis. PLoS One. 2017;12(1):e0169798.

30. Macedo SM, Andrade RPS, Souza CRBA, Andrade ASS, Villa TCS, Pinto ESG. Estratégias para capacitação ao cuidado em tuberculose. Cogitare Enferm. 2016:21(3): 01-08

31. Santos JN, Sales CMM, Maciel EL. Factors associated with cure when treating tuberculosis in the state of Rio de Janeiro, Brazil, 2011-2014. Serv. Saude. 2018:27(3):e2017464.

32. Arcoverde MAM, Berra TZ, Alves LS, Santos DT, Belchior AS, Ramos ACV et al. How do social-economic differences in urban areas affect tuberculosis mortality in a city in the tri-border region of Brazil, Paraguay and Argentina. BMC Public Health. 2018:18:795.

33. Maio MC. Raça, doença e saúde pública no Brasil: um debate sobre o pensamento higienista do século XIX. In: Maio MC, Santos RV. Raça como questão: história, ciência e identidades no Brasil. Rio de Janeiro: Fiocruz; 2010. p. 51-82.

34. World Health Organization (WHO). A conceptual framework for action on the social determinants of health. Geneva: World Health Organization; 2010.

https://www.who.int/sdhconference/resources/ConceptualframeworkforactiononSDH_eng.pdf. Accessed 28 Oct 2020.

35. Marx A. Making race and nation: a comparison of south Africa, the United States and Brazil. Cambridge: Cambridge University Press; 1998. 
36. Oliveira BLCA, Luiz RR. Densidade racial e a situação socioeconômica, demográfica e de saúde nas cidades brasileiras em 2000 e 2010. bras. epidemiol. 2019;22.

37. Chiavegatto Filho ADP, Beltrán-Sánchez H, Kawachi I. Racial disparities in life expectancy in Brazil: challenges from a multiracial society. Am J Public Health 2014;104(11):2156-62.

38. Piergallini T, Turner J. Tuberculosis in the elderly: Why inflammation matters. Exp Gerontol. 2018;105:32-39.

39. Zhang CY, Xia YY, Yu YL, Shen X, Lu W, Wang XM et al. Prevalence and risk factors of active pulmonary tuberculosis among elderly people in China: a population based cross-sectional study. Infect Dis Poverty. 2019;8:7.

40. Rodrigues MW, Mello AGNC. Tuberculose e escolaridade: Uma revisão da literatura. Revista Internacional de Apoyo a la Inclusión, Logopedia, Sociedad y Multiculturalidad. 2018;4(2).

41. Bell LCK, Noursadeghi M. Pathogenesis of HIV-1 and Mycobacterium tuberculosis co-infection. Nat Rev Microbiol. 2018;16(2):80-90.

42. Meintjes G, Brust JCM, Nuttall J, Maartens G. Management of active tuberculosis in adults with HIV. Lancet HIV. 2019;6(7):e463-e474.

43. Tornheim JA, Dooley KE. Tuberculosis Associated with HIV Infection. Microbiol Spectr. 2017;5(1).

44. Silva DR, Muñoz-Torrico M, Duarte R, Galvão T, Bonini EH, Arbex FF et al. Fatores de risco para tuberculose: diabetes, tabagismo, álcool e uso de outras drogas. J bras pneumol. 2018;44(2).

45. Pereira SM, Araújo GS, Santos CAST, Oliveira MG, Barreto, ML. Associação entre diabetes e tuberculose: estudo caso controle. Rev Saúde Pública. 2016;50:82

46. Marais BJ, Lönnroth K, Lawn SD, Migliori GB, Mwaba P, Glaziou P et al. Tuberculosis comorbidity with communicable and non-communicable diseases: integrating health services and control efforts. Lancet Infect Dis. 2013;13(5):436-48.

47. Ayelign B, Negash M, Ganetu M, Wondmagegn T, Shubabaw T. Immunological Impacts of Diabetes on the Susceptibility of Mycobacterium tuberculosis. J Immunol Res. 2019;2019:6196532

48. Restrepo BI. Diabetes and Tuberculosis. Microbiol Spectr. 2016 Dec;4(6):10

49. Wang F, Wang J, Felfand A, Li F. Accommodating the ecological fallacy in disease mapping in the absence of individual exposures. Stat Med. 2017 Dec 30;36(30):4930-4942

50. Brasil. Ministério da Saúde. Secretaria de Vigilância em Saúde. Departamento de Vigilância das Doenças Transmissíveis. Manual de Recomendações para Controle de Tuberculose no Brasil. 2019. https://bvsms.saude.gov.br/bvs/publicacoes/manual_recomendacoes_controle_tuberculose_brasil_2_ed.pdf. Accessed 28 Oct 2020.

\section{Tables}

Table 1. Clinical and epidemiological profile of pulmonary tuberculosis cases and factors related to living in a risk area, Ribeirão Preto, SP, Brazil (2006-2017) 


\begin{tabular}{|c|c|c|c|c|}
\hline Variables & $\begin{array}{l}\text { All reported cases } \\
\text { N (1760) } \\
(\%)\end{array}$ & $\begin{array}{l}\text { Cluster resident cases } \\
\mathrm{N}(680) \\
(\%)\end{array}$ & $\begin{array}{l}\text { Pearson's chi square } \\
\mathrm{X}^{2} \\
\text { (P-value) }\end{array}$ & $\begin{array}{l}\text { Odds Ratio } \\
(95 \% \mathrm{Cl})\end{array}$ \\
\hline \multicolumn{5}{|l|}{ Age } \\
\hline 0 to 14 years & $74(4.2 \%)$ & $32(4.7)$ & $0.69(0.41)$ & $N A$ \\
\hline 15 to 59 years & $1393(79.1)$ & $541(79.6)$ & $0.11(0.73)$ & $N A$ \\
\hline 60 years or older & $277(15.7)$ & $100(14.7)$ & $0.89(0.34)$ & $N A$ \\
\hline Ignored & $16(0.9)$ & $7(1.0)$ & $N A$ & $N A$ \\
\hline \multicolumn{5}{|l|}{ Sex } \\
\hline Male & $531(30.2)$ & $468(68.8)$ & $0.53(0.47)$ & $N A$ \\
\hline Female & $1229(69.8)$ & 212 (31.2) & $N A$ & $N A$ \\
\hline \multicolumn{5}{|l|}{ Race/color } \\
\hline Yellow & $2(0.1)$ & $N A$ & $1.26(0,26)$ & $N A$ \\
\hline White & $704(40.0)$ & $267(39.3)$ & $0.25(0,62)$ & $N A$ \\
\hline Brown & $331(18.8)$ & $143(21.0)$ & $3.58(0,05)$ & $1.26(0.99-1.61)$ \\
\hline Black & $141(8.0)$ & $50(7.4)$ & $0.65(0,42)$ & $N A$ \\
\hline Ignored & $582(33.0)$ & $65(9.6)$ & $N A$ & $N A$ \\
\hline \multicolumn{5}{|l|}{ Years of study } \\
\hline No study & $80(4.5)$ & $36(5.3)$ & $5.26(0.02)$ & $1.71(1.53-1.95)$ \\
\hline 1 to 3 years & $160(9.1)$ & $65(9.6)$ & $0.29(0.59)$ & $N A$ \\
\hline 4 to 7 years & $500(28.4)$ & $198(29.1)$ & $0.27(0.60)$ & $N A$ \\
\hline 8 to 11 years & $241(13.7)$ & 77 (11.3) & $1.43(0.23)$ & $N A$ \\
\hline 12 to 14 years & $51(2.9)$ & $15(2.2)$ & $1.88(0.17)$ & $N A$ \\
\hline 15 years or more & $29(1.6)$ & $17(2.5)$ & $4.96(0.02)$ & $0.73(0.55-0.98)$ \\
\hline \multicolumn{5}{|l|}{ Occupation } \\
\hline Formal work & $141(8.0)$ & $55(8.1)$ & $0.01(0.92)$ & $N A$ \\
\hline Informal work & $194(11.0)$ & $71(10.4)$ & $0.38(0,53)$ & $N A$ \\
\hline Retired & $27(1.5)$ & $5(0.7)$ & $4.68(0.03)$ & $1.35(1.13-1.94)$ \\
\hline Unemployed & $128(7.3)$ & $50(7.4)$ & $0.01(0.91)$ & $N A$ \\
\hline Ignored & $1270(72.1)$ & $498(73.2)$ & $N A$ & $N A$ \\
\hline HIV & & & & \\
\hline
\end{tabular}




\begin{tabular}{|c|c|c|c|c|}
\hline Positive & $313(17.8)$ & $117(17.2)$ & $N A$ & $N A$ \\
\hline Negative & 1447 (82.2) & $563(82.8)$ & $4.38(0.03)$ & $0,55(0.08-0.63)$ \\
\hline \multicolumn{5}{|l|}{ Diabetes } \\
\hline Yes & $84(4.8)$ & $39(5.7)$ & $N A$ & $N A$ \\
\hline No & 1676 (95.2) & 641 (94.3) & $2.25(0.03)$ & $0.35(0.09-0.73)$ \\
\hline \multicolumn{5}{|c|}{ Alcoholism } \\
\hline Yes & $365(20.7)$ & $144(21.2)$ & $N A$ & $N A$ \\
\hline No & 1395 (79.3) & $536(78.8)$ & $0.12(0.71)$ & $N A$ \\
\hline \multicolumn{5}{|c|}{ Mental disease } \\
\hline Yes & $34(1.9)$ & $18(2.6)$ & $N A$ & $N A$ \\
\hline No & 1726 (98.1) & $662(97.4)$ & $2.99(0.08)$ & $N A$ \\
\hline \multicolumn{5}{|c|}{ Drug addiction } \\
\hline Yes & $209(11.9)$ & $91(13.4)$ & $N A$ & $N A$ \\
\hline No & 1551 (88.1) & 589 (86.6) & $2.40(0.12)$ & $N A$ \\
\hline \multicolumn{5}{|l|}{ Smoking } \\
\hline Yes & $123(7.0)$ & $52(7.6)$ & $N A$ & $N A$ \\
\hline No & 1637 (93.0) & $628(92.4)$ & $0.73(0.39)$ & $N A$ \\
\hline
\end{tabular}

\section{Figures}




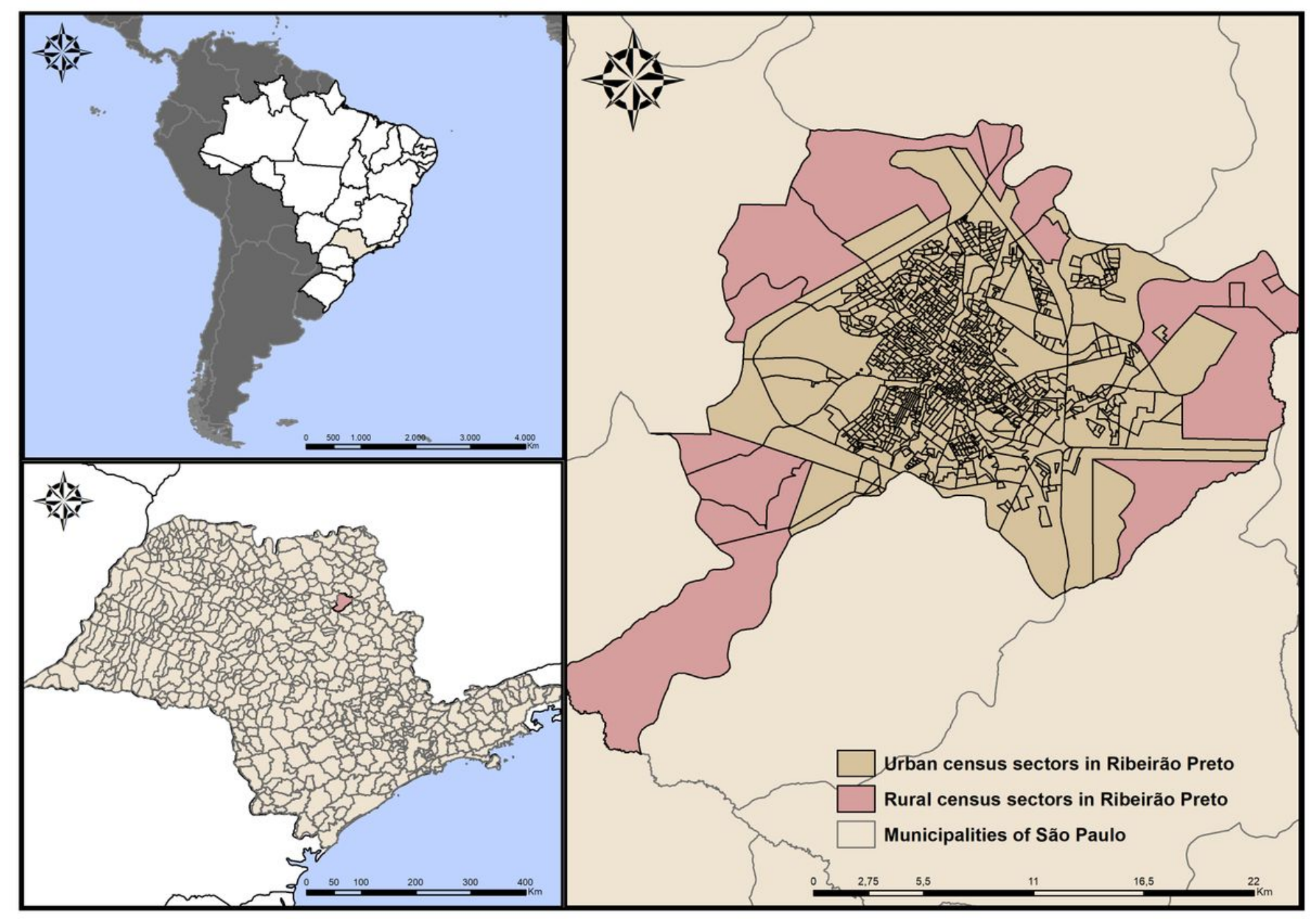

Figure 1

Geographic location of Ribeirão Preto, SP, Brazil (2020).

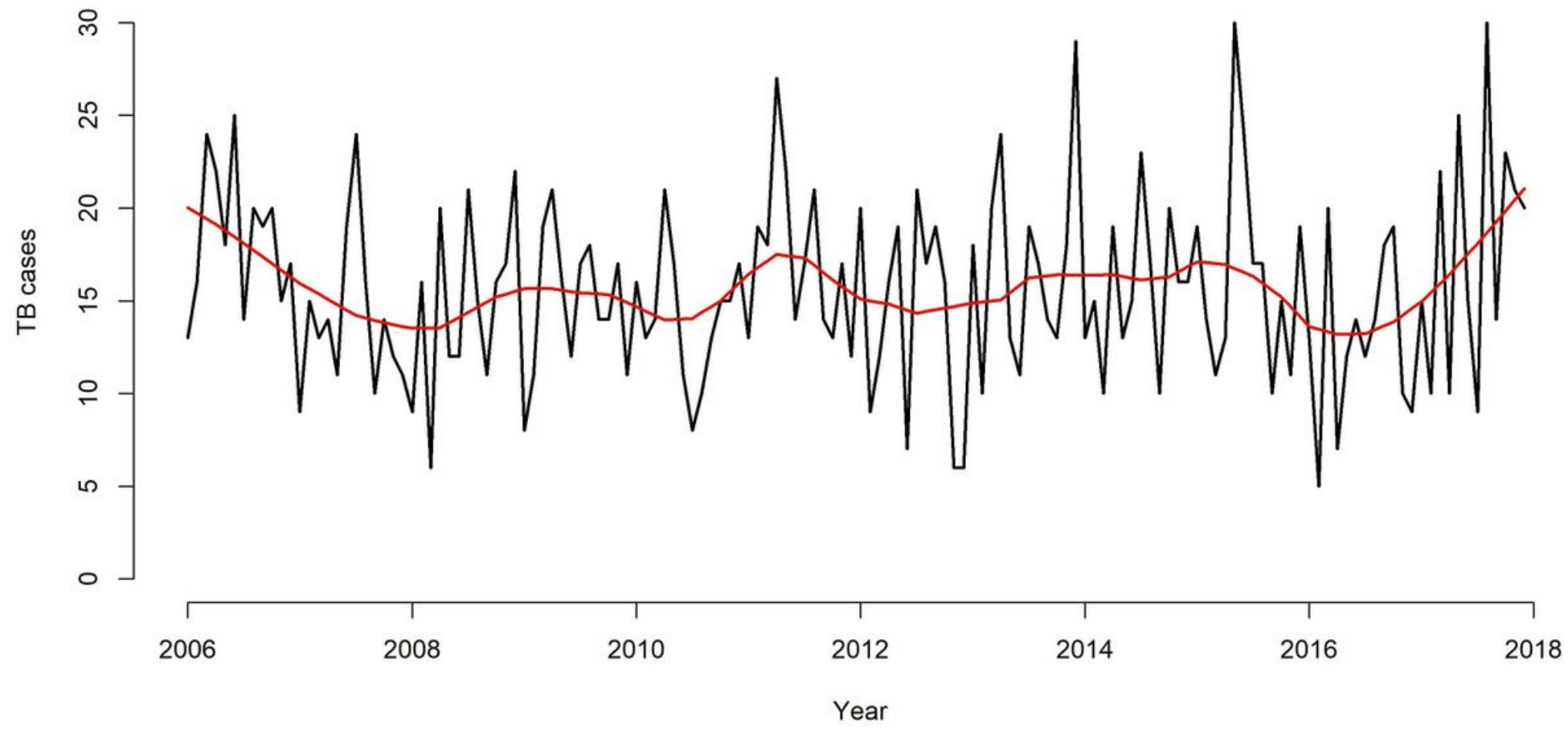


Figure 2

Series and time trend of pulmonary tuberculosis cases, Ribeirão Preto, SP, Brazil (2006-2017).

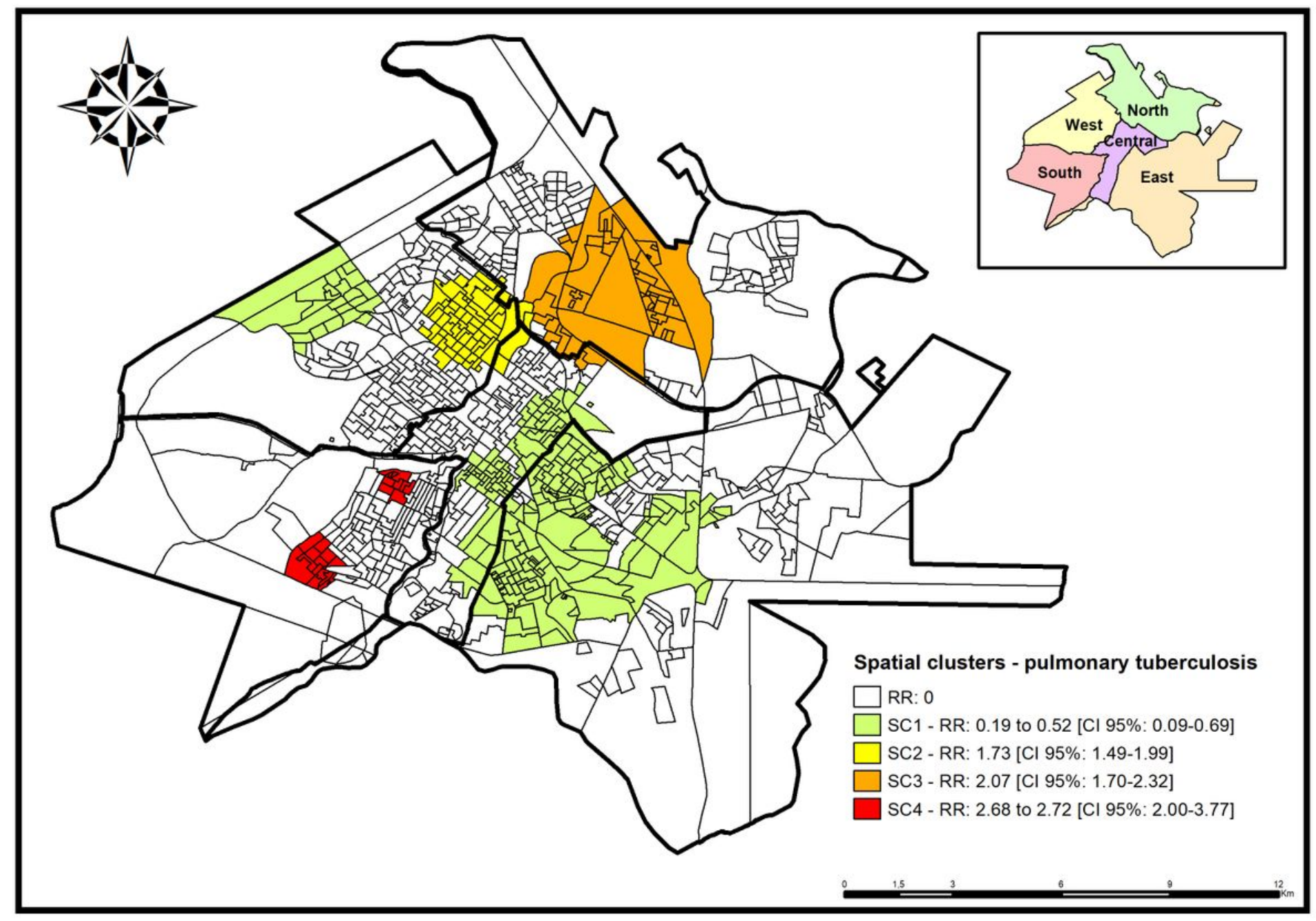

Figure 3

Areas of spatial risk for the occurrence of pulmonary tuberculosis, Ribeirão Preto, SP, Brazil (2006-2017). 


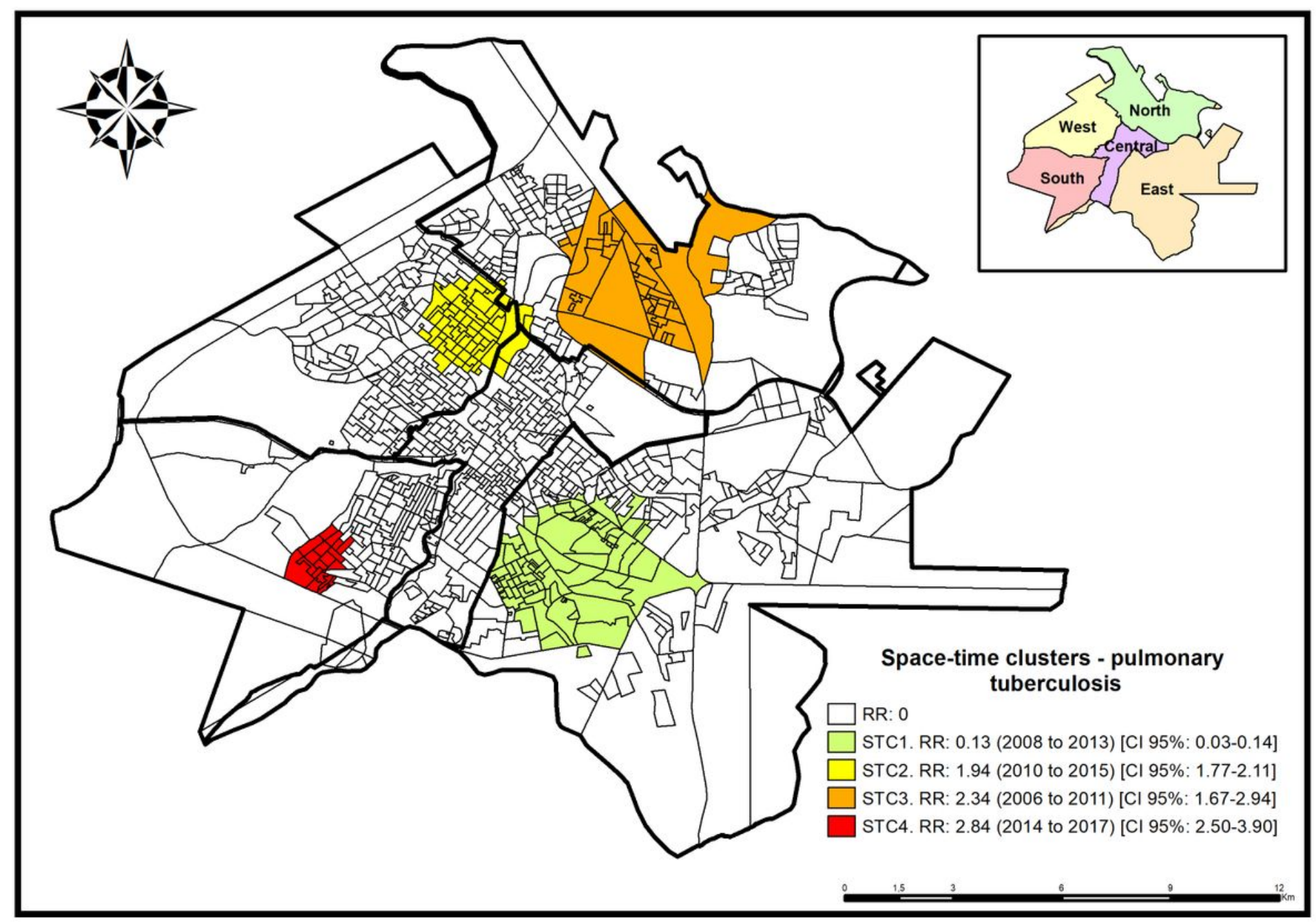

Figure 4

Space-time risk areas for the occurrence of pulmonary tuberculosis, Ribeirão Preto, SP, Brazil (2006-2017). 


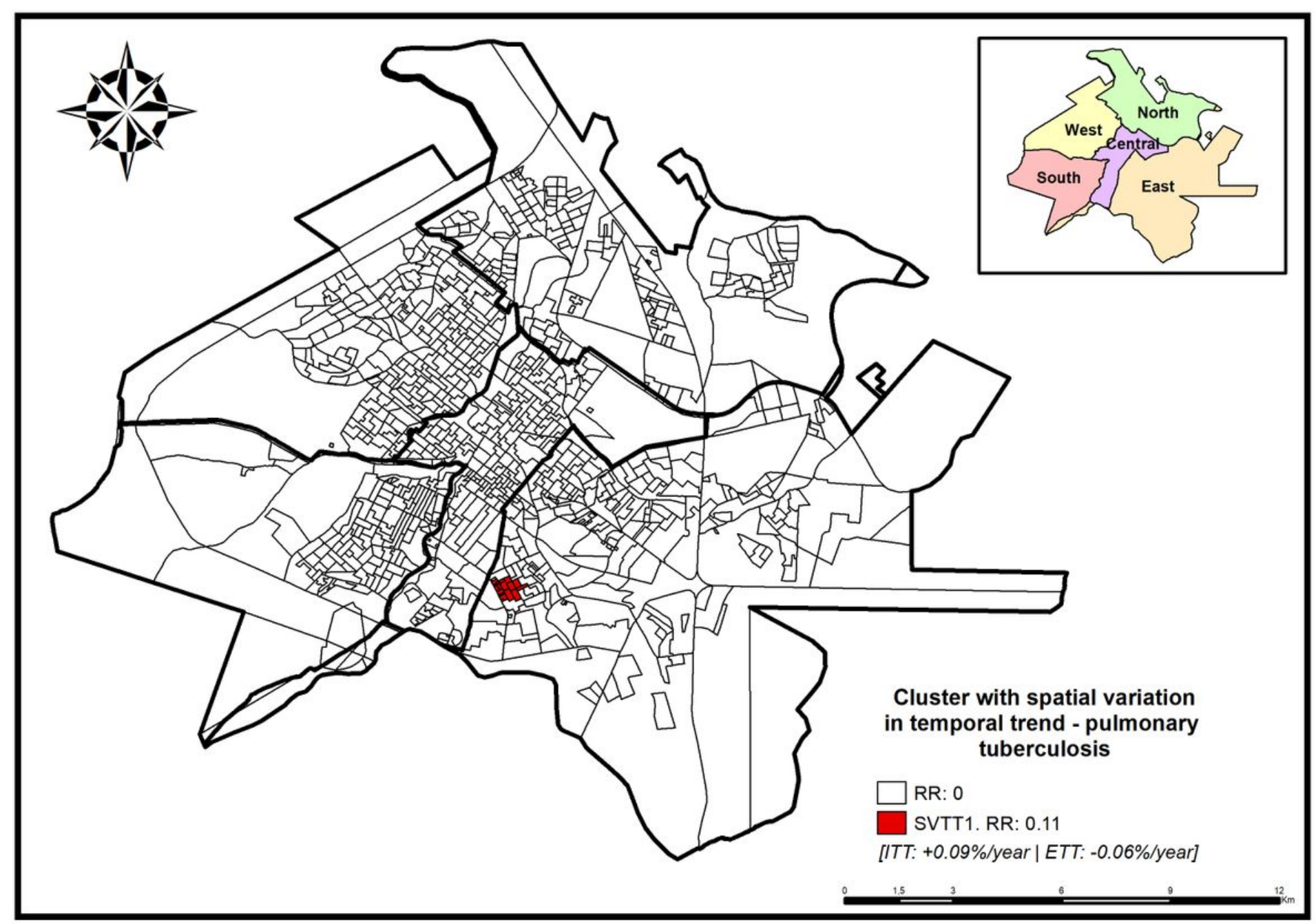

Figure 5

Areas with spatial variation in temporal trends for the occurrence of pulmonary tuberculosis, Ribeirão Preto, SP, Brazil (2006-2017). 